\title{
Retinoids and breast cancer: new clues to increase their activity and selectivity
}

\author{
Enrico Garattini*, Gabriela Paroni and Mineko Terao \\ See related research by Bosch et al., http://breast-cancer-research.com/content/14/4/R121
}

\begin{abstract}
All-trans retinoic acid and derivatives (retinoids) are promising agents in the management of certain hematologic malignancies and solid tumors, including breast cancer. Retinoids are endowed with antiproliferative, cyto-differentiating and apoptotic effects that are largely mediated by activation of the nuclear hormone retinoic acid receptors RARa, RAR $\beta$ and RAR $\gamma$. These are ligand-dependent transcriptional factors controlling the expression of numerous genes. The relative importance of each receptor subtype for the anti-tumor activity of retinoids is largely unknown. Clarification of this point is of fundamental importance for the rational design of retinoid-based therapeutic approaches aimed at controlling a heterogeneous type of tumors, like breast cancer.
\end{abstract}

The results presented by Bosch and colleagues [1] in the previous issue of Breast Cancer Research are a major step towards the identification of the critical determinants controlling the responses of breast tumor cells to alltrans-retinoic acid (ATRA), the prototype of retinoids, a promising class of anti-cancer agents. The authors demonstrate that the two retinoid nuclear receptors RAR $\alpha$ and RAR $\gamma$ play opposite roles in controlling the growth of breast cancer cells [1]. Retinoid-dependent activation of RAR $\alpha$ arrests the growth, while activation of the other receptor favors the proliferation of the neoplastic cell. Suppression of RAR $\gamma$ activity enhances the antiproliferative effects of ATRA in cultures of breast cancer cell lines and in an appropriate animal model of the tumor. Finally, the RAR $\alpha$ agonist AM580 [2] is more effective than the pan-RAR ligand, ATRA [3,4], in controlling the growth of breast cancer cells both in vitro

*Correspondence: enrico.garattini@marionegri.it

Laboratory of Molecular Biology, Istituto di Ricerche Farmacologiche "Mario Negri", via La Masa 19, 20156 Milano, Italy and in vivo. This is consistent with the intrinsic ability of ATRA to activate RAR $\alpha$ and RAR $\gamma$ simultaneously.

ATRA is the only example of a clinically useful cytodifferentiating agent in oncology [3,4], having changed the natural history of acute promyelocytic leukemia, a rare form of acute myelogenous leukemia [5]. This along with promising results obtained in preclinical models has spurred interest in the use of ATRA and natural (9-cis and 13-cis retinoic acid) or synthetic derivatives (retinoids) also for the management of solid tumors, with particular reference to breast cancer. However, the clinical experience accrued with ATRA and derivatives in breast cancer has not kept up with expectations [6]. Indeed, so far, promising results have been obtained only with the atypical synthetic retinoid fenretinide, which is effective in the secondary prevention of pre-menopausal breast tumors [7].

One of the reasons for the poor clinical outcome of ATRA in breast cancer may be linked to the heterogeneity of this tumor, which is a collection of distinct entities with different biological and prognostic characteristics [8]. Thus, the identification of specific markers defining breast cancer subtypes with particular sensitivity to ATRA and derivatives is likely to represent a priority in studies aimed at developing rational therapeutic approaches based on the use of these compounds. Definition of RAR $\alpha$ and RAR $\gamma$ as a positive and a negative determinant of retinoid sensitivity in breast carcinoma [1] is an important step in this direction. In fact, it suggests that breast tumors with high $\mathrm{RAR} \alpha / \mathrm{RAR} \gamma$ ratios should represent optimal targets for retinoids. Two large subgroups of breast cancer with these characteristics have been identified. The first one is represented by estrogen receptor-positive tumors, where estrogens are known to increase the activity of RARA, the gene encoding RAR $\alpha$, while leaving unaffected the RAR $\gamma$-encoding counterpart $[9,10]$. The idea is supported by the observation that estrogen receptor-positive breast carcinoma cell lines are sensitive to ATRA, while estrogen receptornegative ones are not [11]. A second subgroup characterized by high $\mathrm{RAR} \alpha / \mathrm{RAR} \gamma$ ratios has been identified among Her2/neu-positive breast cancers [12]. In fact, 
approximately 20 to $25 \%$ of Her2/neu-positive tumors have been shown to present with co-amplification of the $R A R A$ gene, with consequent high constitutive levels of the encoded receptor. Cell lines recapitulating this genotype are characterized by sensitivity to ATRAdependent anti-neoplastic activity, regardless of the estrogen-receptor status [12] and sensitivity is mediated by RAR $\alpha$. Despite what has been discussed above, the search for tumor subtypes with high RAR $\alpha / R A R \gamma$ ratios may be an oversimplification of the problem. In fact, RARs are not the only nuclear receptors activated by ATRA, which has been demonstrated to stimulate peroxisome proliferator-activated receptor (PPAR) $\beta / \delta$ as well [13]. Interestingly, ATRA-dependent activation of $\mathrm{PPAR} \beta / \delta$ is also associated with increased breast cancer cell growth, which is similar to what has been observed for RAR $\gamma$ [14]. This adds a further layer of complexity to the search for breast tumor subtypes that may benefit from retinoid treatment.

The work of Bosch and colleagues supports the concept that RAR $\alpha$ is the principal mediator of ATRA anti-tumor activity in breast cancer. The authors propose that targeting of RAR $\alpha$ with selective agonists, like AM580, may be a more effective clinical strategy to hit breast cancer cells than a pan-RAR agonist like ATRA. Indeed, the proposed therapeutic strategy may have additional value besides the observed lack of RAR $\gamma$ activation. The use of RAR $\alpha$ agonists should theoretically avoid activation of RAR $\beta$, whose expression in tumor-associated stromal cells is a potential determinant of breast cancer growth [15]. In addition, selective targeting of RAR $\alpha$ may reduce certain aspects of retinoid systemic and doselimiting toxicity, such as skin rashes and intra-cranial hypertension $[3,4]$, two effects that are believed to be mediated by RAR $\gamma$. However, simple activation of RAR $\alpha$ may not be an optimal strategy to counter breast cancer growth and progression, as such an approach does not take into consideration the circulating levels of endogenous ATRA ( 1 to $10 \mathrm{nM}$ ) that are sufficient to activate tumor cells' RAR $\gamma$. Hence, we propose that approaches based on combinations between $\operatorname{RAR} \alpha$ agonists and RAR $\gamma$ antagonists may represent a more rational strategy in the clinical management of breast cancer.

In conclusion, the work of Bosch and colleagues revives interest in retinoids for the treatment and chemoprevention of breast cancer. A rational use of these agents calls for more in-depth knowledge of the molecular mechanisms and determinants underlying the sensitivity/ resistance of the neoplastic cell to ATRA and derivatives. This is likely to result in the development of effective therapeutic protocols based on combinations between retinoids and other anti-neoplastic agents, which is the ultimate goal of this line of research.

\section{Abbreviations}

ATRA, all-trans retinoic acid; PPAR, peroxisome proliferator-activated receptor; $R A R$, retinoic acid receptor.

\section{Competing interests}

The authors declare that they have no competing interests.

Published: 4 September 2012

\section{References}

1. Bosch A, Bertran SP, Lu Y, Garcia A, Jones AM, Dawson MI, Farias EF: Reversal by RARa agonist AM580 of c-Myc-induced imbalance in RARa/RARY expression during MMTV-Mmyc tumorigenesis. Breast Cancer Res 2012, 14:R121.

2. Gianní M, Li Calzi M, Terao M, Guiso G, Caccia S, Barbui T, Rambaldi A, Garattini E: AM580, a stable benzoic derivative of retinoic acid, has powerful and selective cyto-differentiating effects on acute promyelocytic leukemia cells. Blood 1996, 87:1520-1531.

3. Garattini E, Gianni' M, Terao M: Cytodifferentiation by retinoids, a novel therapeutic option in oncology: rational combinations with other therapeutic agents. Vitam Horm 2007, 75:301-354.

4. Garattini E, Gianni M, Terao M: Retinoids as differentiating agents in oncology: a network of interactions with intracellular pathways as the basis for rational therapeutic combinations. Curr Pharm Des 2007, 13:1375-1400.

5. de The H, Chen Z: Acute promyelocytic leukaemia: novel insights into the mechanisms of cure. Nat Rev Cancer 2010, 10:775-783.

6. Cuzick J, DeCensi A, Arun B, Brown PH, Castiglione M, Dunn B, Forbes JF, Glaus A, Howell A, von Minckwitz G, Vogel V, Zwierzina H: Preventive therapy for breast cancer: a consensus statement. Lancet Oncol 2011, 12:496-503.

7. Veronesi U, Mariani L, Decensi A, Formelli F, Camerini T, Miceli R, Di Mauro MG, Costa A, Marubini E, Sporn MB, De Palo G: Fifteen-year results of a randomized phase III trial of fenretinide to prevent second breast cancer. Ann Oncol 2006, 17:1065-1071.

8. Prat A, Ellis MJ, Perou CM: Practical implications of gene-expression-based assays for breast oncologists. Nat Rev Clin Oncol 2011, 9:48-57.

9. Lu M, Mira-y-Lopez R, Nakajo S, Nakaya K, Jing Y: Expression of estrogen receptor alpha, retinoic acid receptor alpha and cellular retinoic acid binding protein II genes is coordinately regulated in human breast cancer cells. Oncogene 2005, 24:4362-4369.

10. Cicatiello L, Mutarelli M, Grober OM, Paris O, Ferraro L, Ravo M, Tarallo R, Luo S, Schroth GP, Seifert M, Zinser C, Chiusano ML, Traini A, De Bortoli M, Weisz A: Estrogen receptor alpha controls a gene network in luminal-like breast cancer cells comprising multiple transcription factors and microRNAs. Am J Pathol 2010, 176:2113-2130.

11. Terao M, Fratelli M, Kurosaki M, Zanetti A, Guarnaccia V, Paroni G, Tsykin A, Lupi M, Gianni M, Goodall GJ, Garattini E: Induction of miR-21 by retinoic acid in estrogen receptor-positive breast carcinoma cells: biological correlates and molecular targets. J Biol Chem 2011, 286:4027-4042.

12. Paroni G, Fratelli M, Gardini G, Bassano C, Flora M, Zanetti A, Guarnaccia V, Ubezio P, Centritto F, Terao M, Garattini E: Synergistic antitumor activity of lapatinib and retinoids on a novel subtype of breast cancer with coamplification of ERBB2 and RARA. Oncogene 2012, 31:3431-3443.

13. Schug TT, Berry DC, Shaw NS, Travis SN, Noy N: Opposing effects of retinoic acid on cell growth result from alternate activation of two different nuclear receptors. Cell 2007, 129:723-733.

14. Schug TT, Berry DC, Toshkov IA, Cheng L, Nikitin AY, Noy N: Overcoming retinoic acid-resistance of mammary carcinomas by diverting retinoic acid from PPARbeta/delta to RAR. Proc Natl Acad Sci U S A 2008, 105:7546-7551.

15. Liu X, Nugoli M, Laferrière J, Saleh SM, Rodrigue-Gervais IG, Saleh M, Park M, Hallett MT, Muller WJ, Giguère V: Stromal retinoic acid receptor beta promotes mammary gland tumorigenesis. Proc Natl Acad Sci U S A 2011, 108:774-779.

doi:10.1186/bcr3245

Cite this article as: Garattini $E$, et al.: Retinoids and breast cancer: new clues to increase their activity and selectivity. Breast Cancer Research 2012, 14:111. 